\title{
Multicompartmental Analysis of Calcium Kinetics in Normal Adult Males*
}

\author{
R. Neer, $\nmid$ M. Berman, L. Fisher, and L. E. Rosenberg $\ddagger$ \\ (From the Metabolism Branch, National Cancer Institute, and the Mathematical Research \\ Branch, National Institute of Arthritis and Metabolic Diseases, National Institutes \\ of Health, Bethesda, Md.)
}

\begin{abstract}
Summary. This report describes studies of calcium kinetics in ten normal young men. Serum, urinary, and fecal radioactivity was measured from 1 minute to 20 days after intravenous tracer ${ }^{47} \mathrm{Ca}$ injection, and these results were analyzed jointly with data obtained from a simultaneous metabolic balance study, using digital computer techniques. Surface radioactivity measurements were also obtained to gain further insight into the anatomic correlates of the tracer distribution. The data were satisfied by a model with four exchanging compartments. Series, branching, and mammillary models were analyzed. Several parameters of physiologic interest were independent of the model, but two were dependent on the duration of the study. Individual and mean values for these kinetic analyses are presented with their statistical uncertainties. These studies present detailed analyses in a healthy, normal population and provide a reference for future studies of skeletal metabolism and serum calcium homeostasis.
\end{abstract}

\section{Introduction}

Since the pioneering work of Bauer, Carlsson, and Lindquist $(1,2)$, many studies of calcium kinetics in man have been undertaken with intravenous ${ }^{45} \mathrm{Ca}$ or ${ }^{47} \mathrm{Ca}$. Values for skeletal accretion and resorption, intestinal absorption and excretion, and renal clearance of calcium have been obtained in a host of disease states with a variety of analytical methods. A major shortcoming of these studies has been the lack of sufficient numbers of normal control subjects. The only paper in the field specifically dealing with normal subjects is based on data from 23 subjects of both sexes ranging in age from 27 to 78 years, studied in seven different laboratories under admittedly different conditions (3). In addition, most of the available studies ignore the rapid phases of serum calcium

\footnotetext{
* Submitted for publication August 8, 1966; accepted May 8, 1967.

† Present address: Massachusetts General Hospital, Boston, Mass.

$\ddagger$ Address requests for reprints to Dr. L. E. Rosenberg, Dept. of Medicine, Yale University Medical School, New Haven, Conn.
}

turnover and examine the slower phases for only 7 to 10 days.

This report describes studies of calcium kinetics in a group of ten young, healthy adult males studied over an 18- to 20 -day period with frequent samplings during the first 24 hours. Combined metabolic balance and isotopic tracer techniques were employed. A rigorous mathematical analysis of both the rapid and slow phases of calcium turnover has been undertaken. The results provide a detailed description of calcium kinetics in a homogenous group of normal adults to serve as a reference for studies of abnormal states.

\section{Methods}

Subjects. The normal subjects for these experiments were healthy men aged 20 to 24 . Each volunteer met the following requirements: no history of chronic or recent acute disease; no bone fractures within 5 years; no dietary faddism; normal physical examination; normal chest $\mathrm{x}$ ray (special attention to lateral view of vertebral bodies); normal hemoglobin, hematocrit, erythrocyte sedimentation rate, and white blood count; normal urinalysis; less than 10,000 colonies of bacteria per milliliter of clean-voided first morning urine; normal blood urea 
nitrogen, sodium, potassium, chloride, bicarbonate, calcium, phosphorus, and alkaline phosphatase. K. B. had renal glycosuria, but all other studies mentioned above were normal in this patient, as were the 24-hour values for urinary calcium, phosphate, potassium, sodium, and $\alpha$-amino nitrogen. Two older volunteers, not included in the analysis of normal values, were selected for a pilot study of the effect of age on calcium kinetics. They also satisfied the requirements listed above. Table I gives further details of the patients studied.

Experimental design. All studies were performed with the informed consent of the volunteer. The study was carried out on the Metabolic Balance Ward of the National Cancer Institute and included the following routine : confinement to the air-conditioned hospital building; light physical activity within the building without strenuous exercise or inactivity; consumption of a constant amount of distilled water; ingestion of a diet of constant composition; and collection of all urine, feces, and vomitus. The methods followed were essentially those outlined by Reifenstein, Albright, and Wells (4), and have been described in detail previously (5). The diets were chosen by each volunteer to approximate his customary intake of calcium and other nutrients. R. Sm. customarily ingested $2.5 \mathrm{~g}$ of calcium; his diet was restricted to a level of calcium intake similar to the other volunteers'. In this study, 3 to 4 weeks of adjustment were allowed before the actual start of the experiment. In all other studies, the trial balance period lasted 5 to 7 days.

The experiment began about 2 hours after breakfast with the rapid injection into an antecubital vein of $10 \mu \mathrm{c}$ of ${ }^{47} \mathrm{CaCl}_{2}$ dissolved in 2 to $10 \mathrm{ml}$ of sterile isotonic saline. Blood samples were taken from the opposite antecubital vein for radioactivity and calcium assays at $1,2,3,4,5,6$, $8,11,15,20,25,30,35,45,60,80,100,120,180,270,360$, 480,600 , and 720 minutes after the isotope injection, and at $1,1.5,2,3,4,5,6$, and 7 days after the injection. For the first 2 hours these samples were collected through an indwelling Cournand needle. The radioactivity in the serum was measured with a Nuclear-Chicago scintillation detector with a $\mathrm{NaI}$ (thallium-activated) Marinellitype crystal and an automatic sample changer. Stable calcium was measured on the same samples (see below), and the radioactivity was expressed as the fraction of the injected dose per gram of calcium. For about 44 hours after the isotope injection, voidings were collected separately and assayed individually for radioactivity. For the next 18 days the radioactivity was measured on 24hour lots of pooled urine. The urine was collected in 2-gallon glass bottles containing $1 \mathrm{ml}$ of concentrated $\mathrm{HCl}$. Stable calcium was measured in the same samples (see below), and the urinary specific activity was expressed as the fraction of the injected dose per gram of calcium. The cumulative radioactivity excreted in the urine was also calculated for each sampling interval and expressed as a cumulative fraction of the injected dose. Fecal specimens were collected for about 20 days after the isotope injection, homogenized, and pooled at variable intervals for radioactivity assays. The radioactivity re-
TABLE I

Experimental subjects

\begin{tabular}{|c|c|c|c|c|}
\hline Subject & Age & Height & Weight & Comments \\
\hline & years & $\mathrm{cm}$ & kg & \\
\hline $\begin{array}{l}\text { J. L. } \\
\text { J. H. } \\
\text { C. D. } \\
\text { P. S. } \\
\text { D. V. } \\
\text { W. H. } \\
\text { R. K. } \\
\text { R. S. } \\
\text { R. Sm. }\end{array}$ & $\begin{array}{l}22 \\
24 \\
21 \\
21 \\
23 \\
22 \\
23 \\
21 \\
22\end{array}$ & $\begin{array}{l}172 \\
185 \\
172 \\
163 \\
176 \\
172 \\
176 \\
185 \\
195\end{array}$ & $\begin{array}{l}68 \\
62 \\
72 \\
60 \\
64 \\
66 \\
74 \\
84 \\
84\end{array}$ & \\
\hline K. B. & 23 & 179 & 78 & $\begin{array}{l}\text { Renal glycosuria; no other } \\
\text { proximal tubular abnor- } \\
\text { malities. }\end{array}$ \\
\hline T. C. & 57 & 169 & 63 & $\begin{array}{l}\text { Psychomotor seizures for } 3 \\
\text { years; died suddenly of } \\
\text { probable intracranial hem- } \\
\text { orrhage } 2 \text { months after } \\
\text { study. }\end{array}$ \\
\hline A. $\mathrm{S}$. & 55 & 173 & 73 & $\begin{array}{l}\text { Bilateral apical blebs on } \\
\text { chest film. }\end{array}$ \\
\hline
\end{tabular}

covered was expressed as the cumulative fraction of the injected dose. Fecal specific activity was not determined, but fecal calcium was measured (see below). All urinary and fecal radioactivity assays were performed on $300-\mathrm{ml}$ homogenized samples, using a specially constructed Sharp scintillation detector with three $\mathrm{NaI}$ crystals (thallium-activated) longitudinally disposed around the circumference of a cylindrical counting jar at $120^{\circ}$ intervals. This arrangement gave excellent counting geometry and permitted a 10 - to 20 -fold improvement in counting efficiency over previous methods used in this laboratory (5). All radioactivity assays of serum, urine, and feces were carried out with radiation analyzers (NuclearChicago model 1810 for serum, Baird-Atomic model 250 for urine and feces) to screen out radiation weaker than $0.4 \mathrm{Mev}$. This eliminated radiation from ${ }^{47} \mathrm{Sc}$, the radioactive decay product of ${ }^{47} \mathrm{Ca}$. All specimens and all backgrounds were counted for a length of time sufficient to ensure a coefficient of variation under $6 \%$ for the net count rate (6). Usually the coefficient of variation was under $3 \%$.

In addition to analysis of blood, urine, and feces, surface radioactivity was measured simultaneously over the left medial malleolus and the right medial thigh at 2,4 , $6,8,10,12,15,18,21,25,30,35,40,45,50,55,60,70,80$, $100,120,180,270,360,480,600$, and 720 minutes after the isotope injection, and at 1, 1.2, 1.4, 1.6, 2, 2.5, 3, 4, 5, 6, $7,8,9,10,11,12,13,14$, and 15 days after the injection. These measurements were made with two separate specially shielded Nuclear-Chicago scintillation detectors with 2-inch $\mathrm{NaI}$ crystals (thallium-activated). Each crystal and detector was surrounded by a minimum of 3 inches of lead. This shielding absorbed $99 \%$ of all ${ }^{47} \mathrm{Ca}$ radiation. A cylindrical hole $5.6 \mathrm{~cm}$ in diameter was cut through the shielding in front of each crystal, and surface radioactivity measurements were made with the subject's skin against the margins of the hole. The sub- 


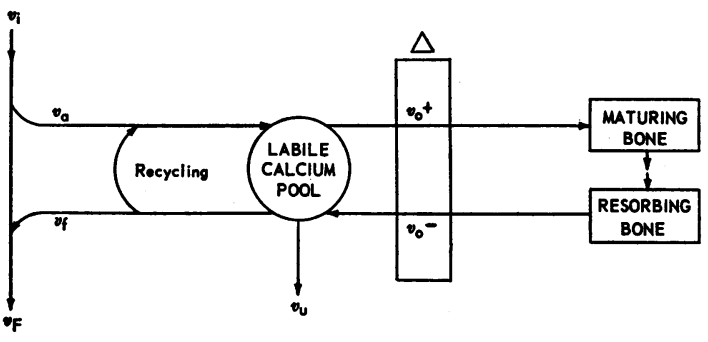

Fig. 1. General scheme of Calcium metabolism, inDICATING THE SPECIAL SYMBOLS USED IN THE TEXT. Large circle represents the labile calcium pool. Arrows to the left represent calcium movement through and across the gut. Arrows to the right represent skeletal accretion, maturation, and resorption. Arrow below represents renal excretion.

ject was positioned so that each detector registered radioactivity from only a single extremity. Radiation analyzers (Nuclear-Chicago model 132) screened out radiation weaker than $1.1 \mathrm{Mev}$. This eliminated radiation from ${ }^{4} \mathrm{Sc}$ and minimized scatter radiation due to Compton interactions between tissue in front of the counter and ${ }^{4} \mathrm{Ca}$ photons arising elsewhere in the body. During the first 120 minutes of the experiment the subject was immobilized in front of the counters. Subsequently, repositioning was effected by means of appropriate marks on the detector and the subject's skin. Rapid sequential counting after the count rate had stabilized indicated that the fluctuation in count rate attributable to repositioning alone was about $5 \%$. To minimize this further, all surface measurements after the initial 120 minutes were done twice, with repositioning each time, and the average of the two was employed. Sufficient patient and background counts were collected to ensure a coefficient of variation under $6 \%$ for the average net count rate. The surface radioactivity detected depends upon local tissue and detector geometry, $\boldsymbol{\gamma}$-ray absorption in the tissues, and the sensitivity of the detector. We have not attempted corrections for these variables. $\mathrm{Be}$ cause of shielding difficulties, surface radioactivity measurements on the earlier studies had to be discarded as unreliable; data are available only for the last five young adult subjects in Table I.

For all assays of radioactivity in serum, urine, feces, and body surface, a weighed sample of the injected dose of ${ }^{47} \mathrm{Ca}$ was simultaneously assayed as a standard. The dose given the patient was determined by weighing the syringe and needle before and after the injection. The error resulting from traces of blood retained in the syringe was insignificant so long as the weight of the injected dose was $2 \mathrm{~g}$ or more. The ${ }^{n 7} \mathrm{Ca}$ was obtained commercially ${ }^{1}$ and assayed for purity, activity, sterility, and pyrogenicity by the Radiation Safety Office, NIH, before administration to patients. The ${ }^{87} \mathrm{CaCl}_{2}$ was essentially carrier-free.

1 Union Carbide Co., Oak Ridge, Tenn.
The calcium balance study began approximately 44 hours after the initiation of the kinetic study and continued coincident with it. A blue stool marker (7) was given orally at the start of the balance study and repeated at 6-day intervals for the next 18 days. Feces collected before the passage of the first stool marker were assayed for radioactivity and for calcium but were not included in the balance study. Urine collected before administration of the marker was treated similarly. Feces were pooled between markers, after radioactivity assays. Urine was pooled in 24-hour lots as described above. Three 24-hour diet duplicates were collected at approximately 1-week intervals. Diets and feces were lyophilized and ashed three times in a muffle furnace before the calcium assays. Urine and serum were analyzed directly. All were assayed for calcium by precipitation with ammonium oxalate and titration with ammonium hexanitratocerate (8). In this laboratory this method gives 95 to $107 \%$ recovery of calcium standards and calcium added to serum, urine, or feces. The coefficient of variation on repeated analyses of the same serum sample on the same day was $\pm 0.8 \%$. Diet samples were always analyzed in triplicate; all other samples in duplicate. For diet and feces this replication included the triple ashing. The range of replicate assays was always less than $3 \%$ and usually less than $2 \%$ for all samples. A calcium standard and an oxalate standard were assayed with each group of samples.

Data analysis. We have analyzed all data in terms of a compartmental model, employing the following notation: $M_{1}=$ grams of calcium in compartment $i$ of the labile calcium pool; $\boldsymbol{\gamma}_{1 \mathrm{j}}=$ fractional rate of calcium transfer into compartment $i$ from compartment $j$ in units of days $^{-1} ; \rho_{1 j}=\lambda_{1 j} M_{1}=$ amount of calcium transferred into compartment $i$ from compartment $j$ in grams per day; $F_{1}=$ amount of calcium transferred into compartment $i$ from areas outside the labile calcium pool in grams per day.

We have followed the notation of Aubert and Milhaud (9) in assigning special symbols for certain $\rho_{11}$, as follows (Figure 1): $\mathrm{V}_{1}=$ calcium ingested in the diet in grams per day; $\mathrm{V}_{\mathbf{u}}=$ calcium excreted in the urine in grams per day; $V_{F}=$ calcium excreted in the feces in grams per day; $\Delta=V_{1}-V_{u}-V_{z}=$ calcium balance in grams per day; $V_{t}=$ calcium secreted into the gut and then excreted in the feces (endogenous fecal calcium) in grams per day. This does not include calcium secreted into the gut and then reabsorbed; $\mathrm{V}_{\mathrm{a}}=$ calcium absorbed from the gut in grams per day. This is calculated (10) according to the equation $\mathrm{V}_{\mathrm{a}}=\mathrm{V}_{1}+\mathrm{V}_{\mathrm{s}}-\mathrm{V}_{\mathrm{z}}$ (see Figure 1). This equation assumes that the amount of calcium within the gut remains constant during the study; $\mathrm{V}_{\circ}{ }^{+}=$calcium deposited internally in nonexchanging or very slowly exchanging form in grams per day; $\mathrm{V}_{0^{-}}^{-}=$ calcium returned to the labile pool from the nonexchanging or very slowly exchanging deposits in grams per day. This is calculated (10) according to the equation $\mathrm{V}_{0^{-}}^{-}=$ $\mathrm{V}_{0}^{+}-\Delta$. Positive or negative calcium balance is thus attributed to imbalance of $\mathrm{V}_{0}^{+}$and $\mathrm{V}_{0}^{-}$, rather than to alterations in the mass of the labile calcium pool. 
We have also assigned special symbols for the corresponding $\lambda_{1}$, as follows: $\lambda_{\mathrm{u}}=$ fractional rate constant for urinary calcium excretion; $\lambda_{t}=$ fractional rate constant for fecal calcium excretion; $\lambda_{2}=$ fractional rate constant for dietary calcium absorption; $\lambda_{0}{ }^{+}=$fractional rate constant for calcium deposition internally in nonexchanging or very slowly exchanging form.

For surface radioactivity measurements we have employed the notation: $\sigma_{k 1}=a$ proportionality constant relating the fraction of the injected dose in compartment $i$ to the net counts per minute registered in detector $k$. It depends upon the fraction of compartment i "seen" by detector $\mathrm{k}$, as well as other variables discussed previously.

Theoretical considerations. There are two basic assumptions inherent in the present analysis, first, that the labile calcium pool in each subject is in a steady state, and second, that the system is compartmentalized. The first assumption is reasonable, since the studies were done only after equilibration to a constant regimen, and there were no significant changes in serum and urine calcium and phosphorus during the studies. The second assumption is consistent with the data, makes the mathematical analysis relatively simple, and is intuitively appealing.

As a consequence of these assumptions $(11,12)$, the transport of tracer calcium into and out of compartments, $i$, is described by linear first-order differential equations with constant rate coefficients,

$$
\begin{aligned}
\left(\mathrm{df}_{1} / \mathrm{dt}\right)=\lambda_{11} \mathrm{f}_{1}+\lambda_{12} \mathrm{f}_{2}+\cdots-\lambda_{11} \mathrm{f}_{1}-\lambda_{21} \mathrm{f}_{1} \\
-\cdots(\mathrm{i}=1,2, \ldots, \mathrm{n}),
\end{aligned}
$$

where $f_{1}$ is the amount of tracer in compartment $i$, and $\lambda_{1}$, is the rate coefficient as defined above.

To determine the minimum number of compartments necessary for the model, all the data from a single study were fitted jointly to sums of exponentials, using the digital computer program SAAM developed by Berman, Weiss, and Shahn (13-15). Four exponentials were necessary and sufficient to satisfy the data from $5 \mathrm{~min}$ utes to 20 days. Hence, four exchanging compartments were proposed for the model. These define the labile calcium pool.

The most general four-compartment model possible has 16 rate coefficients $\left(\lambda_{11}\right)$ and four paths of calcium entry. The available data are insufficient to quantify all these parameters (15), since they define only eight constants. Additional assumptions must, therefore, be introduced in choosing a model. Some investigators (16) have preferred not to specify a particular compartmental model and have analyzed the data entirely with sums of exponentials. Most have assumed a particular model. Aubert and Milhaud (9) and Marshall (17) preferred a mammillary (parallel) model. Aubert and Milhaud also analyzed branching models, as did Maletskos (in studies on dogs ) (18), Cohn and co-workers (19-21), and Bauer and Ray (22). Finally, Krane, Brownell, Stanbury, and Corrigan (23), Dow and Stanbury (24), Jasinski and associates (25), and Glass and Nordin (26) all preferred a series model.

We chose to analyze the data in terms of all three types of models because there are no criteria for choosing

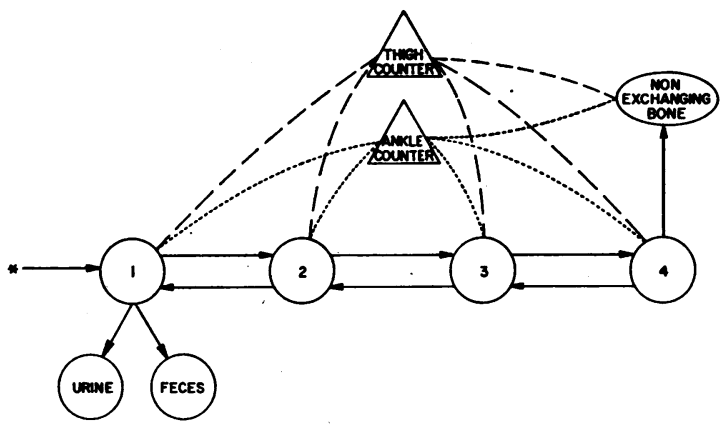

Fig. 2. FuRThER DETAILS OF COMPARTMENTAL MODEL USED IN THE ANALYSIS. Starred arrow represents site of ${ }^{47} \mathrm{Ca}$ injection. Circles are functional compartments within the labile calcium pool. Solid arrows represent transfer of calcium between compartments and loss of calcium to urine, feces, and nonexchanging bone. Broken lines indicate contribution of compartments to surface radiation detectors (triangles).

one type over another (27). Analysis of several models also indicates how sensitive certain features are to the choice of model. The series model analyzed is shown in Figure 2. Urinary calcium is lost directly from compartment one because it is anatomically reasonable and because the cumulative urinary radioactivity was exactly proportional to the integral of the plasma specific activity (Figure 3B). Fecal calcium is assumed to come directly from compartment one because it seems anatomically reasonable, and the data cannot resolve calcium mixing in the gut. For the same reasons calcium absorbed from the the diet is assumed to enter compartment one directly. Urinary and fecal radioactivity do not account for all the ${ }^{\text {" }} \mathrm{Ca}$ lost from the labile calcium pool (1). The remainder represents internal loss to "nonexchanging bone." Nonexchanging is a strictly relative term; data collected over a longer interval (30 days) separate out an additional very slowly exchanging compartment (28). For this reason we have chosen the most slowly exchanging compartment of each model as the site of this loss, although other sites were investigated (see Discussion). Calcium returned to the labile pool from nonexchanging bone is assumed to enter compartment one because it is thought to represent largely bone resorption. It is probably more reasonable to split this flow into two parts (29). One, representing very slow physical-chemical exchange, could return to compartment four. The other, representing cellular resorption, could return to compartment one. However, it is impossible to resolve these pathways with the data available.

Computational procedures. Data fitting was accomplished by means of an iterative process using the computer program SAAM (13-15). Initial estimates of parameter values were automatically adjusted until a least squares fit to all the data was obtained. The goodness of fit was judged by visual inspection. The uncertainties of the fit were given by the variances and covariances obtained for the parameter values. These 
procedures were used for fitting data to sums of exponentials and to differential equations describing the model.

All data from a single study were fitted simultaneously to a single set of model parameters. The data included measurements of plasma, urinary, fecal, and surface radioactive calcium, as well as diet, urinary, and fecal stable calcium.

The compartment sizes and flow rates of stable calcium were calculated from the set of simultaneous equations derived from the steady state conditions: $F_{1}+\lambda_{11} M_{1}+$ $\lambda_{12} \mathrm{M}_{2} \ldots-\lambda_{11} \mathrm{M}_{1}-\lambda_{21} \mathrm{M}_{1}-\ldots=0 \quad(\mathrm{i}=1,2, \ldots$, $n$ ), with the additional constraint that $M_{1}=1 / q_{1}(0)=$ reciprocal of plasma specific activity at zero time, and the assumption (see above) that calcium $\mathrm{V}_{a}$ and $\mathrm{V}_{0}^{-}$entered the labile calcium pool only via compartment one.

The surface counts, $q_{k}$, were fitted under the hypothesis that they represented a linear combination of radioactivity from the various body compartments:

$$
\mathrm{q}_{\mathrm{k}}=\sum_{\mathrm{i}=1}^{\mathrm{n}} \sigma_{\mathrm{ki}} \mathrm{f}_{\mathrm{i}}
$$

This relationship is shown diagrammatically in Figure 2.

The parameter values from the studies on the ten normal young men were averaged to get a weighted group mean for each parameter. The weight given the parameters of each study was based on the variances and covariances of the parameters for that study, in accord with a maximal likelihood estimate developed by Pettigrew (30). Correlations among all parameters for the ten studies were also derived.

To test whether an individual could fall within the normal group, the fit for that individual was biased toward the mean normal values to the degree permitted by his data. This was done by fitting model parameters to the individual's data and to the mean normal values simultaneously, the latter being weighted by their variances and covariances (31). The individual was considered normal if the values so obtained fell within the range of the normal reference group.

\section{Results}

Calcium balance data. The measured calcium intake in these healthy young men ranged from 612 to $1,325 \mathrm{mg}$ per day on their customary diets. This is in the normal range (32). Urinary calcium ranged from 135 to $410 \mathrm{mg}$ per day with a mean of 274 for the group. Five of the subjects had an average urinary calcium greater than 300

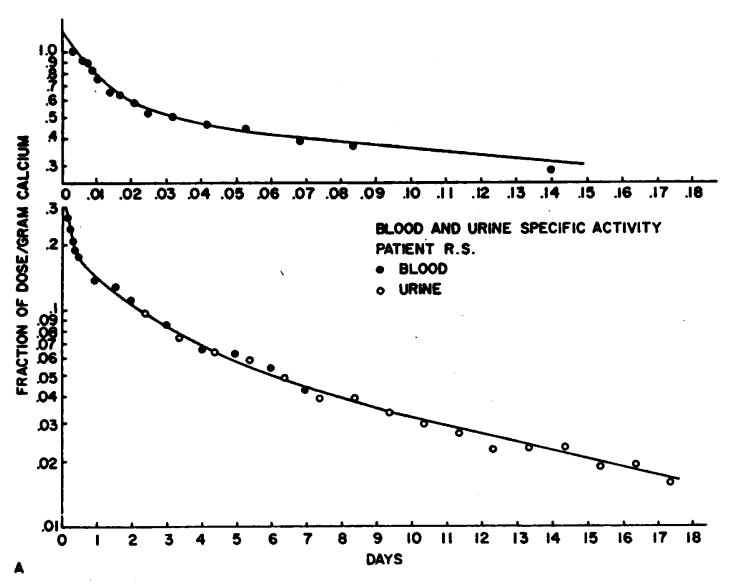

FIG. 3A.

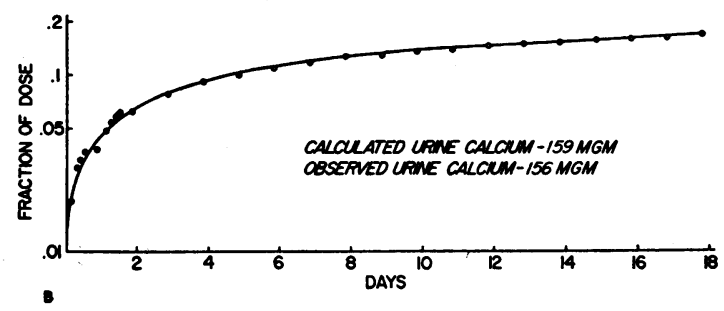

Frg. 3B.

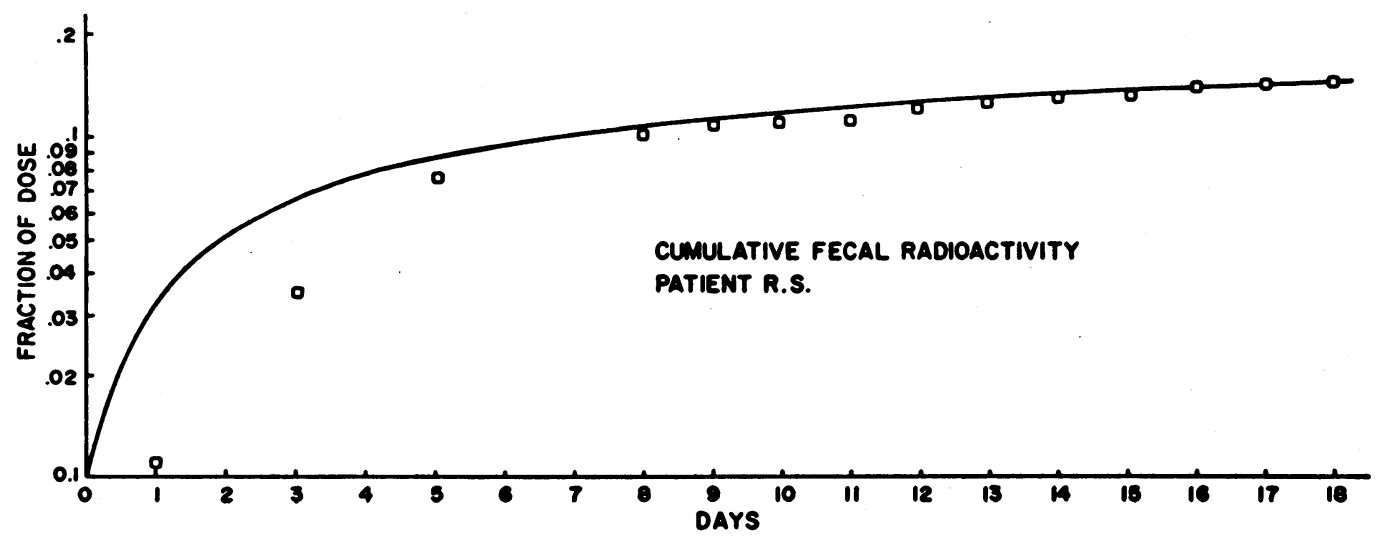

C

FIG. 3C. 


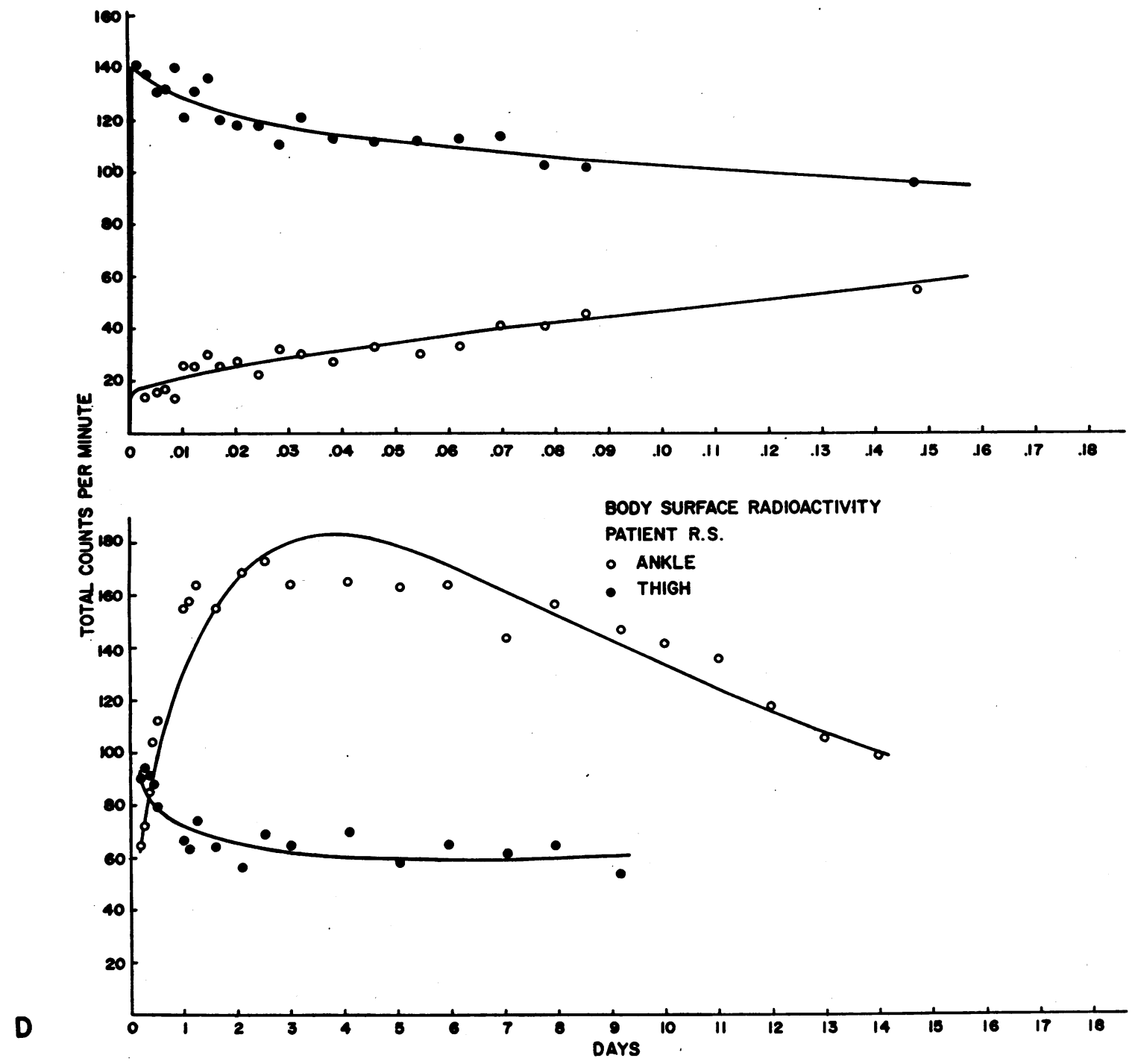

Fig. 3D.

Fig. 3, A, B, C, D. Data fit for Representative subject (R. S.). The solid lines represent computed values. Figure 3, A, is a semilogarithmic plot of specific activity in serum (dots) and urine (circles). Figure 3, B and C, are semilogarithmic plots of cumulative urinary and fecal ${ }^{47} \mathrm{Ca}$ excretion. Note the poor agreement of observed and calculated fecal ${ }^{47} \mathrm{Ca}$ excretion, due to intestinal transit time. Figure 3, D, is an arithmetic plot of surface radioactivity over the ankle (circles) and thigh (dots). Note the expanded time scale in the upper portion of A and D.

mg per day. Calcium balance varied from -174 to $+109 \mathrm{mg}$ per day. The variations from strict equilibrium confirm previous work by others (4) and may be explained by changes in activity imposed by the hospitalization or by failure to account for all calcium losses.

Calcium kinetic data. Figure 3, A, illustrates a typical result for the decline of specific activity in blood and urine after intravenous ${ }^{47} \mathrm{Ca}$. The solid dots are observed blood specific activities; open circles are the observed urinary specific activities. The good agreement illustrated for plasma and urinary specific activities after $\mathbf{4 8}$ hours is typical of our experiments. With a few exceptions other workers have found a similar agreement, (33). Accordingly, the last part of the curve is based on urinary specific activity alone. The blood radioactivity became too low to measure within 1 week 


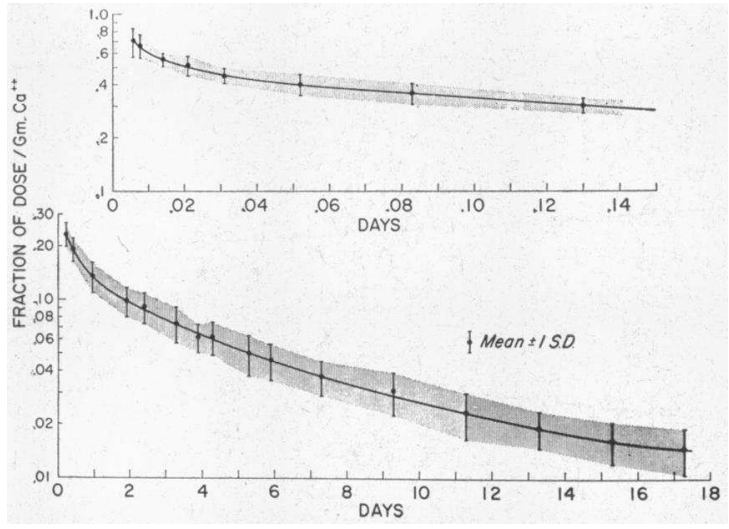

Fig. 4. Composite semilogarithmic cURve of SERUM AND URINE SPECIFIC ACTIVITY IN TEN VOLUNTEERS. Values represented are means $\pm 1 \mathrm{SD}$. Alternate points have been omitted for simplicity. Note change in time scale between the upper and lower portions of the figure.
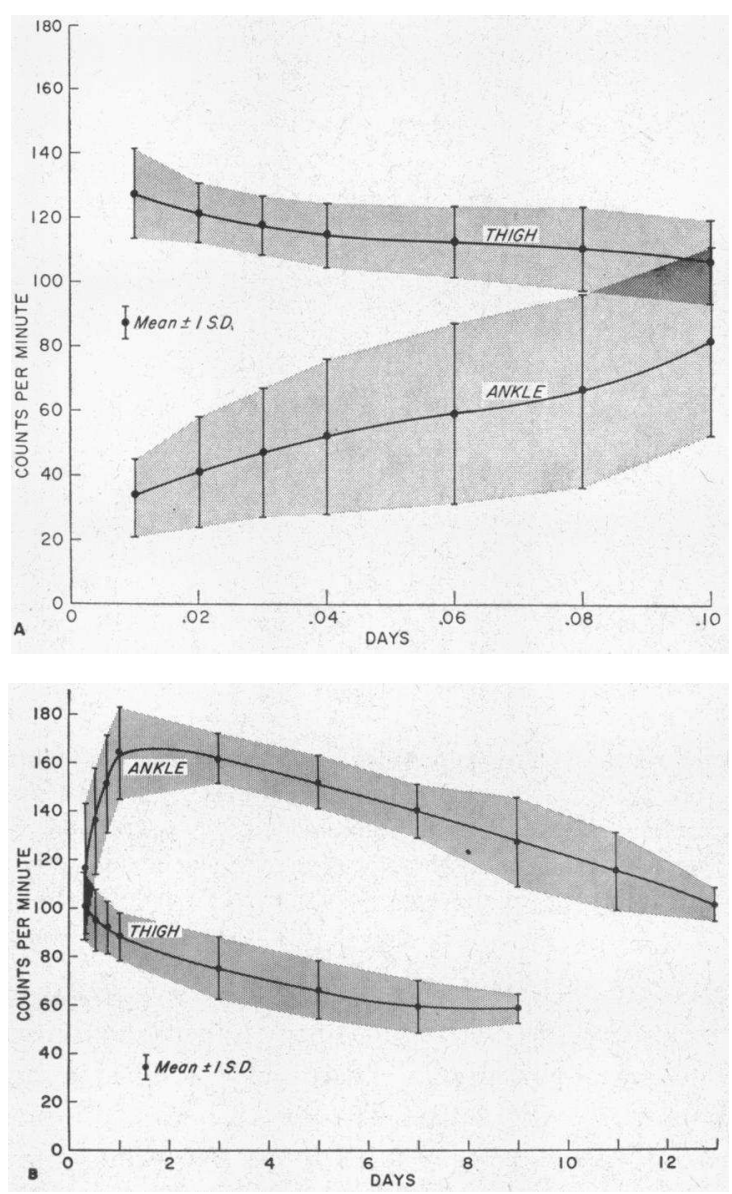

Fig. 5, A and B. Composite surface radioactivity MEASUREMENTS IN FIVE NORMAL SUBJECTS. Values represented are group means $\pm 1 \mathrm{SD}$. Note the expanded time scale in A. after the ${ }^{47} \mathrm{Ca}$ administration. Most of the radioactivity in urine and feces appeared in the first few days after intravenous tracer injection (Figure 3, B and $\mathrm{C}$ ). These results qualitatively parallel those reported by other investigators $(1-3,9,16,19$ $26,34)$. Figure $3, \mathrm{D}$, shows typical radioactivity measurements over the thigh and ankle. The thigh radioactivity rose rapidly to a maximum within 10 to 20 minutes, then declined slowly and was too low to measure after 8 to 10 days. Radioactivity over the ankle built up more slowly before declining and could be detected for 12 to 15 days. These results are similar to those previously reported by Bauer and Ray (22) in studies with radioactive strontium.

The normal range of blood and urinary specific activity in the ten studies, represented as the mean $\pm 1 \mathrm{SD}$, is shown in Figure 4. The similarity of the results is apparent from the small standard deviations. Figure 5, A and B, show the normal range for surface radioactivity measurements, represented as the mean values $\pm 1 \mathrm{SD}$. Although these data were available for only five subjects, the scatter was much greater than for the specific activity data. This is probably related to the variables discussed in Methods, for which we have made no corrections. The Appendix gives
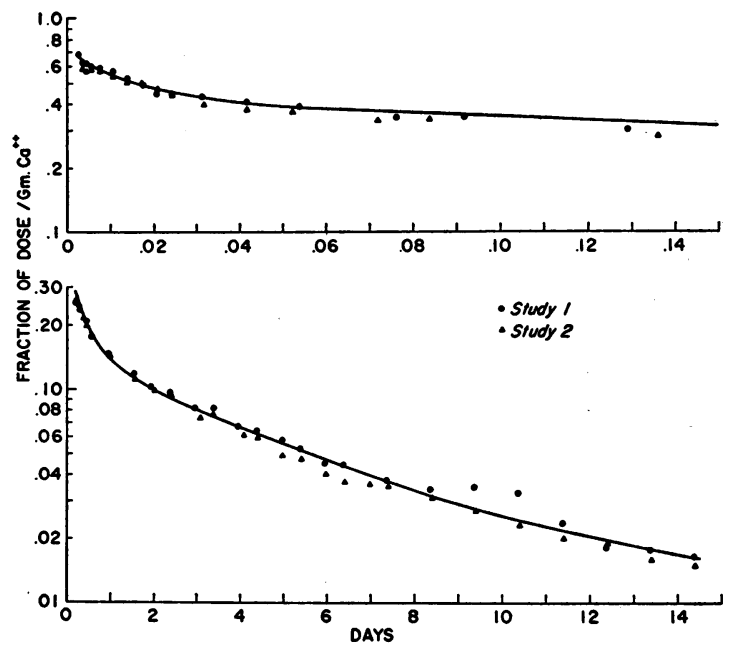

Fig. 6. Blood AND URINE SPECIFIC ACTIVITy DATA FROM IDENTICAL STUDIES 3 MONTHS APART IN SUBJECT J. H., ILlUStrating RePRodUCibility OF RESUlts. Dots represent data from study 1 , triangles data from study 2 ; solid line is curve derived from computer analysis of study 1. Note change in time scale between upper and lower graphs. 

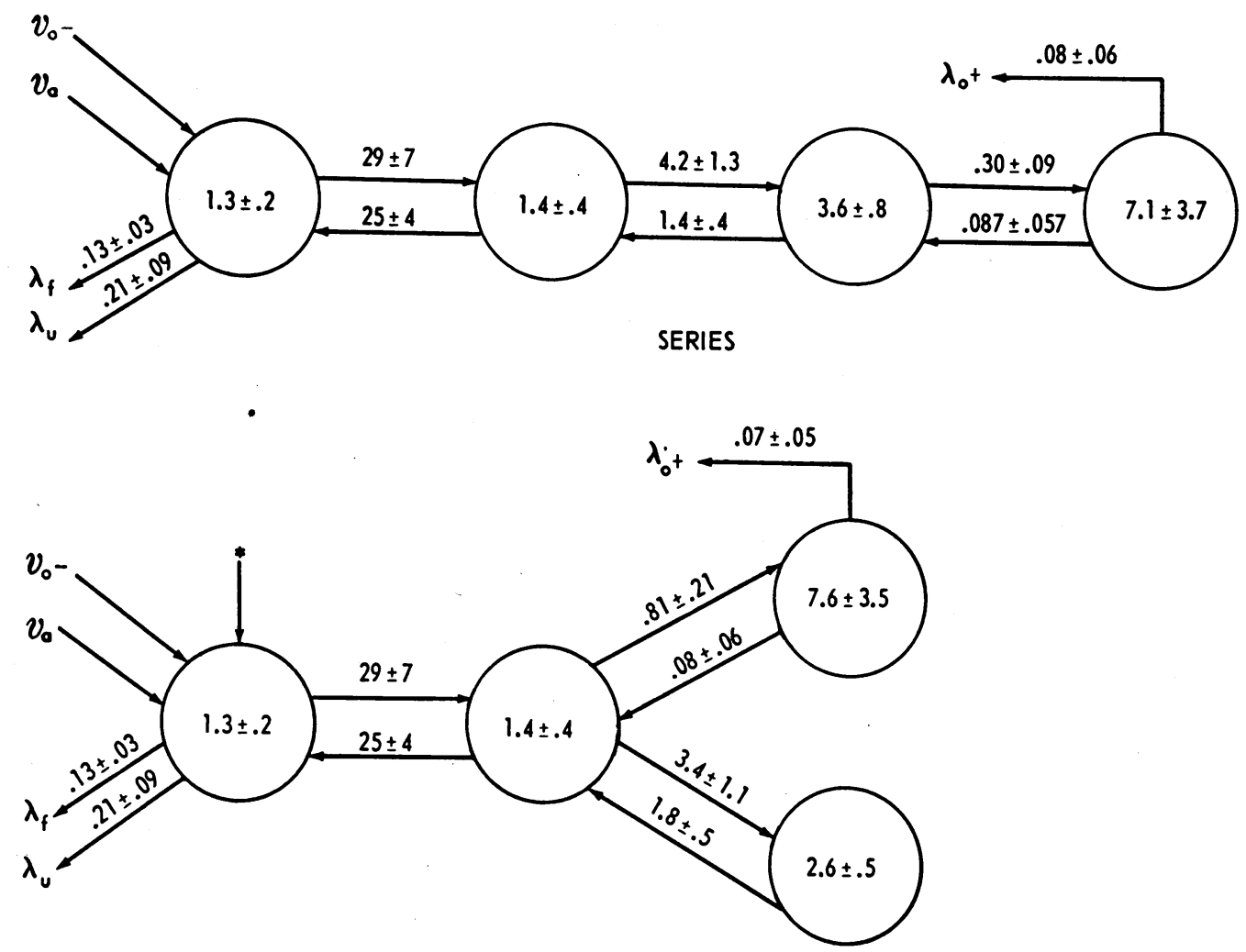

BRANCH

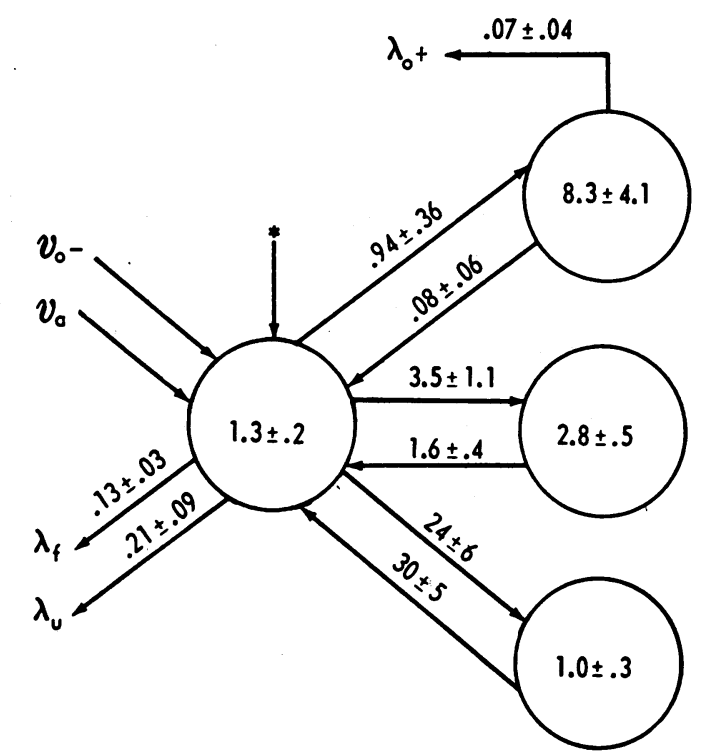

MAMMILLARY

Fig. 7. Final ReSUlts of data ANALYSis fOR EACH COMPARTMENTAL MODEL. All values represent mean $\pm 1 \mathrm{SD}$ for ten normal subjects. To obtain the uncertainties of the mean values, divide the standard deviations by $\sqrt{10}$. Numbers above the arrows are rate constants for calcium transfer, in fractions per day. Corresponding average values for grams of calcium transferred appear in Table II. Numbers within circles are compartment sizes, in grams of calcium. Note invariance of rate constants for intestinal absorption and excretion' and renal excretion. 


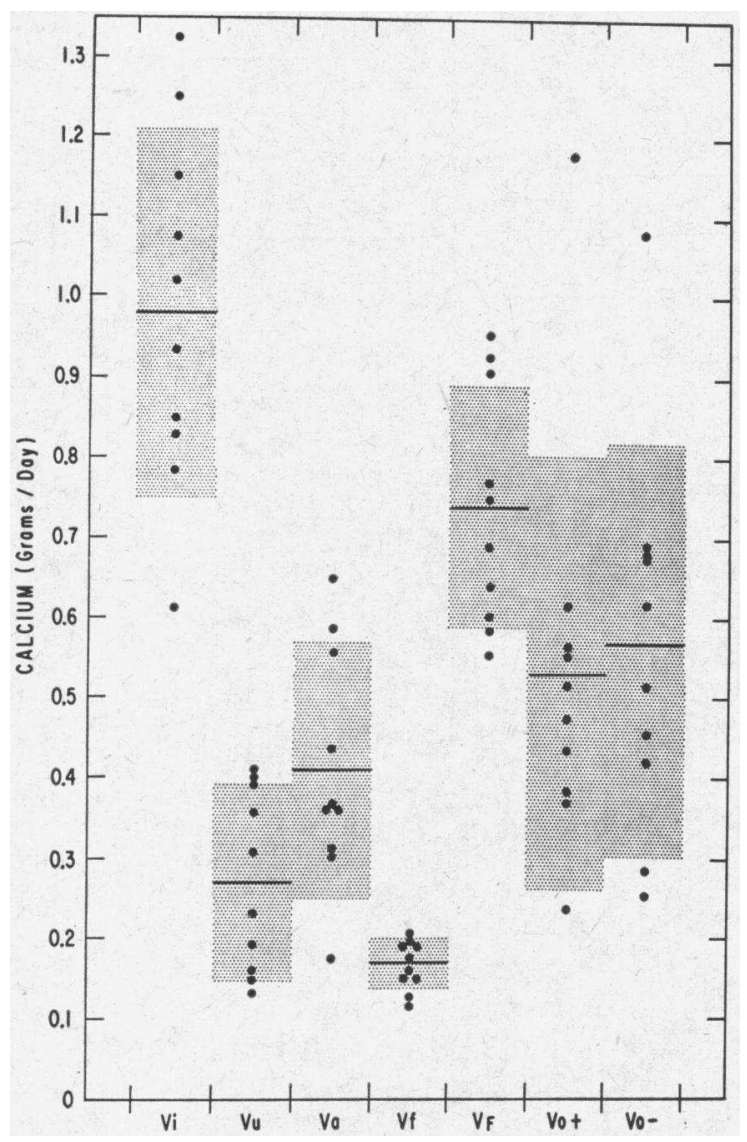

Fig. 8. Stable calcium exchanges that Were INDEPENDENT OF THE MODEL USED FOR ANALYSIS. Each dot represents a single study. Horizontal line and shaded areas indicate mean $\pm 1 \mathrm{SD}$ for the group of ten normal subjects. To obtain the uncertainties for the mean values, divide standard deviations by $\sqrt{10}$. Plotted values for means and standard deviations are below (from left to right).

$\mathrm{V}_{\mathrm{i}}=0.982 \pm 0.234$

$\begin{aligned} & V_{f}=0.167 \pm 0.032 \\ & V_{0}-=0.568 \pm 0.253\end{aligned}$

$V_{n}=0.274 \pm 0.118$
$V_{F}=0.740 \pm 0.149$

$\mathrm{V}_{\mathrm{a}}=0.411 \pm 0.155$
$\mathrm{~V}_{\mathrm{o}^{+}}=0.534+0.270$

weighted mean values for the exponential equations that described the raw data and a tabulation of "average data" for a typical experiment. These formulations allow use of the results without resort to the compartmental models.

Figure 6 illustrates the reproducibility of the kinetic method employed. These two studies in one person, done under identical circumstances 3 months apart, indicate that results can be quite reproducible when the conditions of the experiment are rigidly controlled. Measurements of urinary and fecal radioactivity and urinary and fecal stable calcium were similarly reproducible in this subject.
Compartmental analysis. The success of the compartmental analysis at fitting the kinetic data is apparent from Figure 3. The solid lines in these figures are the mathematical calculations based on the compartmental models. The dots represent data from subject $R$. S. The analysis simultaneously satisfied the urinary stable calcium measurements (Figure 3, B). Figure 3, C, shows the poor fit to cumulative fecal radioactivity in the early phases of the experiment. We attribute this to a lag in isotope excretion caused by intestinal transit. The delay was present even in the subjects who had frequent daily stools, suggesting that ${ }^{47} \mathrm{Ca}$ entered the gastrointestinal tract primarily in the upper levels. We have made no effort to correct the model for intestinal transit. Instead, we have used only the final fecal datum to calculate the fecal excretion rate. Since the fecal radioactivity excretion curve plateaus after the first 6 to 10 days, a lag in the timing is not critical for the final data. Figure 3, D, shows a fit to the ankle radioactivity data from days 1 to 14 . This is a relatively poor fit and occurred in this patient only.

The average results of the compartmental analysis in the group of ten normal men, together with the standard deviations in the group, are shown in Figure 7 for the series, branch, and mammillary models described previously. Note the constancy from model to model of the rate constants for intestinal absorption and excretion and for renal excretion. Some bulk calcium transfers were also constant for each of the three models analyzed. These invariant results include internal calcium movements of major physiological interest: the amount of calcium absorbed and excreted by the intestine $\left(V_{a}\right.$ and $\left.V_{f}\right)$ and the amount of calcium lost to and resorbed from nonexchanging bone $\left(\mathrm{V}_{0}^{+}\right.$and $\left.\mathrm{V}_{0}^{-}\right)$. The values for $\mathrm{V}_{0}^{+}$and $\mathrm{V}_{0}^{-}$were also unchanged if the loss $\left(\mathrm{V}_{0}^{+}\right)$occurred from a compartment other than that shown in Figures 2 and 7 . Individual values for these and some other calcium transfers of interest are shown in Figure 8. As expected, there was considerable variation from subject to subject in intestinal absorption $\left(\mathrm{V}_{\mathrm{a}}\right)$, skeletal resorption $\left(\mathrm{V}_{\mathrm{o}^{-}}\right)$and accretion $\left(\mathrm{V}_{0}^{+}\right)$, and renal excretion $\left(\mathrm{V}_{\mathrm{u}}\right)$. However, there was a striking uniformity in intestinal calcium excretion $\left(V_{f}\right)$ in the ten studies. Average values for the remaining internal calcium ex- 
TABLE II

Average stable calcium exchanges between compartments

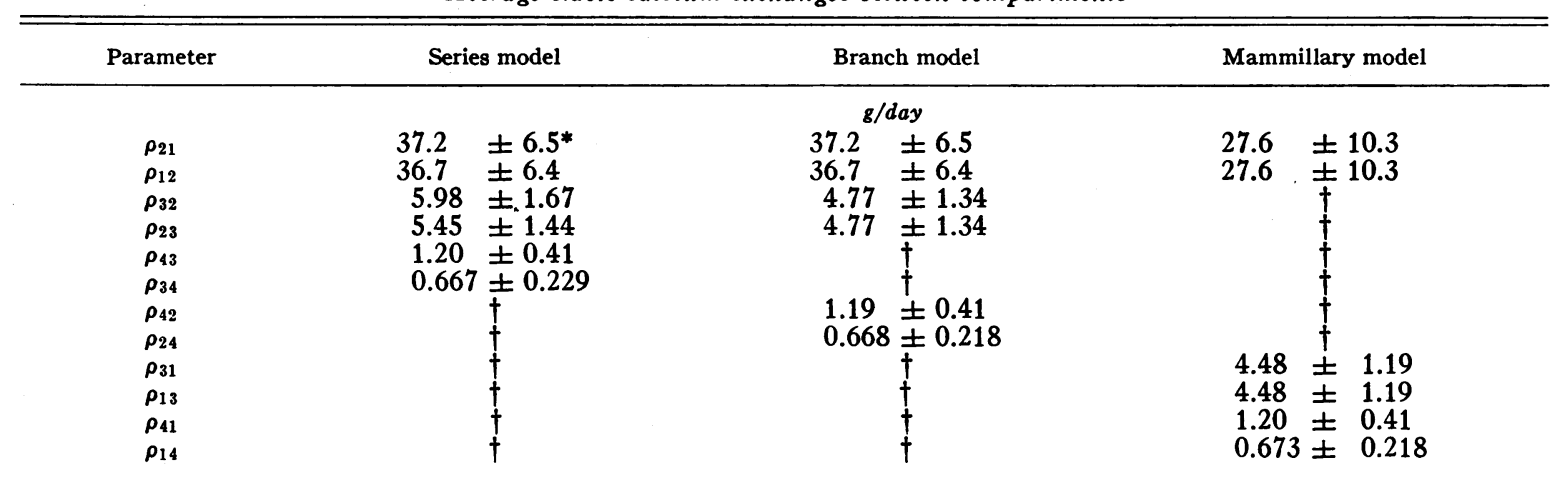

* All values represent mean $\pm 1 \mathrm{SD}$ for a group of ten young men. To obtain the standard errors of the mean, divide the standard deviations by $\sqrt{10}$.

$\dagger$ Not present in model.

changes appear in Table II. In the series and branching models these results differed only with respect to compartment three. In all three of these models the exchanges between compartments three and four were nearly identical.

The coefficients relating body surface radioactivity to the compartmental models were also averaged; the results appear in Table III. The large standard deviations in Table III reflect the uncontrolled variables, which affect surface radioactivity measurements as discussed in Methods. Because of these variables, the coefficient $(\sigma)$ for a given compartment varies from person to person. It likewise varies from place to place over the body, making a comparison of coefficients from the ankle and thigh detectors difficult. It is valid to compare the coefficients of different compartments at the same location. With the ankle detector the coefficients of compartments three and four were much larger than coefficients of compartments one and two. This was true in all three models. This suggests that the ankle counter "sees" primarily the slowly exchanging compartments of the models. The thigh counter has larger coefficients for compartments one and two than for compartments three and four. It "sees" the rapidly exchanging compartments to a greater extent than the slowly exchanging compartments. With both counters and in all three models the coefficient for the nonexchanging bone is much lower than the corresponding coefficients for compartments three and four. This suggests that the

TABLE III

Average surface radioactivity coefficients $(\sigma)^{*}$

\begin{tabular}{|c|c|c|c|}
\hline Parameter & Series model & Branch model & Mammillary model \\
\hline \multicolumn{4}{|l|}{ Ankle } \\
\hline $\begin{array}{l}\text { Compartment one } \\
\text { Compartment two } \\
\text { Compartment three } \\
\text { Compartment four } \\
\text { Nonexchanging bone }\end{array}$ & $\begin{array}{l}23 \pm 11 \dagger \\
57 \pm 52 \\
208 \pm 82 \\
235 \pm 118 \\
63 \pm 45\end{array}$ & $\begin{array}{r}23 \pm 11 \\
55 \pm 52 \\
182 \pm 101 \\
242 \pm 121 \\
62 \pm 46\end{array}$ & $\begin{array}{r}18 \pm 3 \\
80 \pm 12 \\
157 \pm 100 \\
248 \pm 131 \\
54 \pm 52\end{array}$ \\
\hline Thigh & . & e & \\
\hline $\begin{array}{l}\text { Compartment one } \\
\text { Compartment two } \\
\text { Compartment three } \\
\text { Compartment four } \\
\text { Nonexchanging bone }\end{array}$ & $\begin{array}{r}123 \pm 23 \\
93 \pm 36 \\
77 \pm 15 \\
75 \pm 45 \\
45 \pm 21\end{array}$ & $\begin{array}{r}123 \pm 23 \\
95 \pm 35 \\
70 \pm 19 \\
80 \pm 46 \\
45 \pm 20\end{array}$ & $\begin{array}{r}123 \pm 23 \\
99 \pm 39 \\
72 \pm 18 \\
82 \pm 44 \\
44 \pm 20\end{array}$ \\
\hline
\end{tabular}

* $\sigma$ notation defined in Methods.

$\dagger$ All values represent mean $\pm 1 \mathrm{SD}$ for five young men. To obtain the standard errors of the means, divide the standard deviations by $\sqrt{5}$. 


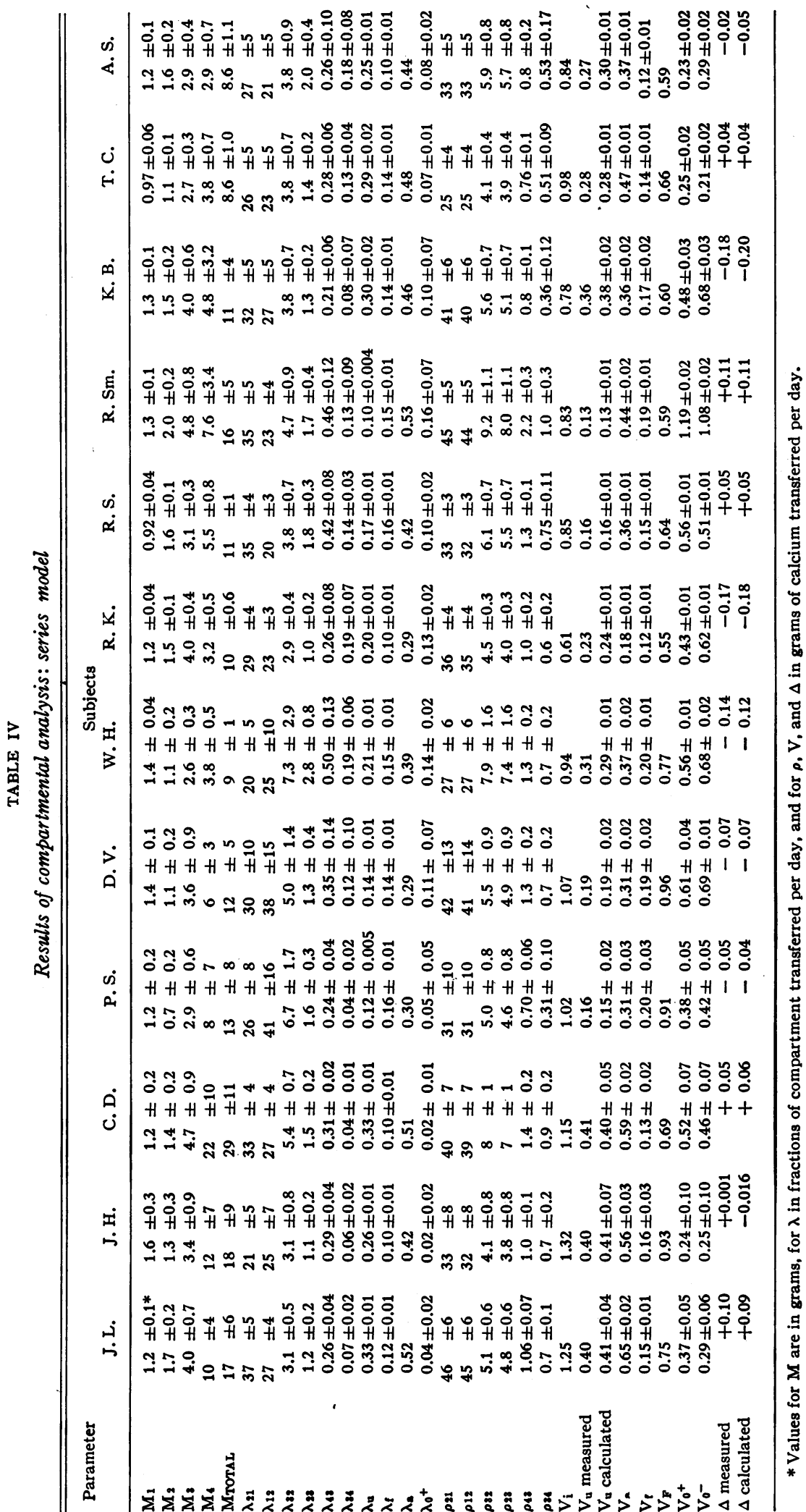


counters "see" a smaller fraction of this nonexchanging calcium.

The detailed results of the compartmental analyses and calcium balances appear in Table IV, using the series model. Similar results for the mammillary and branching models are available on request.

Analysis of results in older men. We have studied two older men and compared their results with the average results for the younger men, using the comparative technique outlined in Methods. The results of this comparison are listed in Table IV for the series model. Values for the labile calcium pool $\left(\mathrm{M}_{\mathrm{T}}\right), \mathrm{V}_{\mathrm{o}^{+}}$, and $\mathrm{V}_{\mathrm{o}}^{-}$were all lower than for most of the normal young men. More older men must be studied to determine whether these differences are statistically significant. No other significant differences were detected in any of the three models.

\section{Discussion}

The present studies were undertaken to establish normal values for calcium kinetics in a homogenous control group. The techniques and results of the calcium balance studies are similar to those of previous investigators and require no comment except for the urinary calcium values. Six of our ten normal young adult subjects had urinary calcium above $200 \mathrm{mg}$ per day; three had urinary calcium of $400 \mathrm{mg}$ or more per day. All had normal serum calcium and phosphorus values and no evidence of renal calculi or bone disease. These results are not surprising in view of the normal calcium diet ingested by our subjects (600 to $1,300 \mathrm{mg}$ per day). The widely accepted value of less than $200 \mathrm{mg}$ for the normal daily urinary calcium is based on studies of individuals consuming a low-calcium diet.

Comparison of the results of the kinetic analysis with previous studies is more complicated. The present studies integrate data on both radioactive and stable calcium collected over a 3-week period. Most previous studies of calcium kinetics have been performed over shorter intervals of time with less complete data collection or analysis. Since the tracer data describe multiexponential curves, data collected over different regions of the curves may lead to the formulation of different models or different parameter values for the same model. Under these circumstances, one can only compare the values for parameters that are common to different models. The parameters common to almost all previous models are $\mathrm{V}_{\mathrm{u}}, \mathrm{V}_{\mathrm{f}}, \mathrm{V}_{\mathrm{a}}, \mathrm{V}_{\mathrm{o}}{ }^{+}$, and $\mathrm{V}_{0}{ }^{-}$. We have compared the values obtained for these parameters with our model and the values obtained with the data for only the earlier parts of our studies. This comparison was made under the following conditions: it was assumed that any set of data included total excreta from $t=0$ up to the termination of the study, and that the extrapolation of the specific activity curve beyond the last observed value followed a single exponential, with a rate constant extrapolated from the data immediately preceding it.

Under these conditions $V_{u}, V_{f}$, and $V_{a}$ were independent of the duration of the experiment. The value of $\left(\mathrm{V}_{0}^{+}-\mathrm{V}_{0}^{-}\right)$was also constant. The value of $\mathrm{V}_{0}^{+}$, however, was as follows, using representative data: ${ }^{2}$ 1-day study, $\mathrm{V}_{\mathrm{o}}{ }^{+}=0.708 ; 4$-day study, $\mathrm{V}_{\mathrm{o}}^{+}=0.665 ; 10$-day study, $\mathrm{V}_{\mathrm{o}^{+}}=0.603$; 20-day study, $\mathrm{V}_{0}^{+}=0.572$. The value of $\mathrm{V}_{0}^{-}$ varied in parallel, since $\mathrm{V}_{0}^{+}-\mathrm{V}_{0}^{-}$was constant.

A more detailed comparison with previous studies and one avoiding the above assumptions would require fitting all data to the same model, regardless of where the observations were made. This is orrly possible with a model such as ours with sufficient structure to include all regions of the observation space. Although some parameter values in the present model are very uncertain with limited data, it is possible to test within what statistical range they agree with known reference values. This testing feature can also be used with more complete data, as in our analysis of the results in the two older men.

The proposed compartmental model is merely a conceptualization of the calcium system as "seen" by the isotope kinetics technique. Although there may be a one-to-one correspondence between a compartment and an anatomic or physiologic entity, this is not likely. Compartments can be viewed as operational entities, useful to describe

2 The following equation was employed to calculate the above: $V_{o}+\left(t_{m}\right)=1-f_{m}\left(t_{m}\right)-\lambda_{m}\left[f_{1}\left(t_{m}\right) / \lambda_{m}\right]$, where $\mathrm{V}_{0}^{+}\left(t_{m}\right)$ is the value of $\mathrm{V}_{0}^{+}$for an experiment of duration $t_{m}, f_{\mathbb{E}}\left(t_{m}\right)$ is the cumulative excretion of urine and feces up to time $t_{m}, f_{1}\left(t_{m}\right)$ is the amount of labeled calcium in plasma at time $t_{m}, \lambda_{m}$ is the estimate of the extrapolated final exponential decay constant of plasma, and $\lambda \mathrm{s}$ is the fractional excretion rate of plasma calcium. 
and analyze the system. Similarly, the rate constants $(\lambda)$ are not likely to represent a single physiological process, but rather the result of multiple processes that cannot be resolved. The calculation of a set of model parameters from a single set of data gives no insight into the nature or significance of these physiologic processes. Studies of the effects of hormonal changes, dietary variations, and so forth, on the parameters may help to associate them with particular physiological processes.

Compartment one represents the site into which the isotope was injected and from which blood samples were taken. As such it must include the vascular space. However, it is four times larger than the vascular calcium space, which suggests penetration of capillary walls, adsorption to endothelial surfaces, or both. Compartment one is also not equivalent to the extracellular calcium mass, calculated on the basis of body weight. This may be due to rapid adsorption of the ${ }^{47} \mathrm{Ca}$ to connective tissue structures and bone crystals. The explanation is probably even more complex, as suggested by one unpublished experiment in which we gave ${ }^{47} \mathrm{Ca}$ subcutaneously, followed by plasma sampling at frequent intervals. The rate of isotope movement into the circulation was slower than would have been predicted from the rapidly exchanging compartments and faster than expected from the slower exchanging ones. This suggests that the extracellular fluid is not just one of our four compartments but probably contributes to several. Aubert and Milhaud (9) defined an earlier fifth compartment representing the vascular calcium space. We were unable to obtain consistent results for the initial 5 minutes of the experiments and could not resolve the vascular compartment, despite careful attention to injection technique and sampling conditions.

Compartments two, three, and four of the model represent progressively slower exchange with the plasma calcium in compartment one. Together with compartment one they comprise the labile calcium pool defined by a 20-day study. This value represents less than $1 \%$ of the estimated total body calcium (35). Efforts were made to identify the compartments anatomically through external counting over thigh and ankle. The results suggest that compartments one and two predominate over the thigh and therefore reflect mainly soft tissue. Since compartments three and four pre- dominate over the ankle, they probably reflect mainly bone. Previous investigators have also considered the slowly exchanging body calcium to be primarily bone (1). Human cadaver analyses by Heaney $(29,36)$ show that ${ }^{47} \mathrm{Ca}$ injected intravenously shortly before death equilibrates with extraskeletal calcium within 2 days, so that the calcium mass defined as nonequilibrating in the model is also probably confined to the skeleton. Nonetheless, the external counters "see" a smaller percentage of the ${ }^{47} \mathrm{Ca}$ in this compartment than that in compartments three and four. This discrepancy is unexplained.

Although it was not possible to choose among different models, certain derived parameters or measures of special interest were independent of the particular model chosen. For any four-compartmental model, the calculated fractional and absolute rates of renal excretion, intestinal absorption, and intestinal secretion were identical, provided they were coupled to compartment one. These calculations depend only on the observed decline of plasma specific activity, the observed pattern of ${ }^{47} \mathrm{Ca}$ excretion, and the observed calcium intake and losses. The calculated amounts of calcium moving out of $\left(\mathrm{V}_{0}^{+}\right)$and into $\left(\mathrm{V}_{0}^{-}\right)$the labile pool were also independent of the interconnections within the pool, provided that $\mathrm{V}_{0}-$ entered compartment one directly. With this limitation, the values of $\mathrm{V}_{0}^{+}$and $\mathrm{V}_{0}^{-}$were also the same regardless of the compartment from which $\mathrm{V}_{0}{ }^{+}$ exited.

The proposed model is the "simplest" compartmental model required to fit the present data. For some purposes such complete data collections are desirable. For example, it is known that parathyroid hormone affects calcium metabolism very rapidly (in less than 48 hours). A kinetic study that leaves out the first 48 hours after isotope injection may fail to detect some of these effects. Similarly, the analysis of changes from one steady state to another should include the rapidly turning over phases of body calcium, since they may be involved in the adjustments. For some other purposes it is unnecessary to collect such extensive data, especially when one is interested in functions that are relatively insensitive to model structure or that require relatively little data for their evaluation. The proposed model, even though it is underdetermined, can still be employed with such 
data. Since the computed solution yields estimates of uncertainties, the adequacy of limited data can be tested. One can also determine what new data are needed to achieve a desired precision (37). When data are inadequate, reference values of an appropriate population may be added to obtain the "best" estimates for the desired function (see Methods). To take full advantage of the possibilities of the general model, it is necessary to establish reference values, standard deviations, and correlation coefficients for the parameters not only for normals but also for various classes of abnormals.

Further understanding of calcium homeostasis may be obtained by studying the effects of vitamin $\mathrm{D}$, parathormone, thyrocalcitonin, variations of calcium intake, and so forth, on calcium kinetics. Such steady state and nonsteady state variations may alter one or more of the model parameters and thus provide a means for further investigation and resolution of the metabolic processes underlying the model and for further testing of the various models. Such studies are now in progress.

\section{Appendix}

Average normal data, Part 1. The data for each experiment were initially fit to sums of exponentials of the following form: blood and urinary specific activity (fraction of dose per gram calcium $)=K_{1}\left(A_{1} e^{-\alpha_{1} t}+A_{2} e^{-\alpha_{2} t}+A_{3} e^{-\alpha_{3} t}\right.$ $\left.+A_{4} e^{-\alpha_{4}}\right)$, where $A_{1}+A_{2}+A_{3}+A_{4}=1$. Cumulative urinary radioactivity (fraction of dose) $=\lambda_{u} \int\left(A_{1} e^{-\alpha_{1} t}\right.$ $\left.+\mathrm{A}_{2} \mathrm{e}^{-\alpha_{2} t}+\mathrm{A}_{3} \mathrm{e}^{-\alpha_{3} t}+\mathrm{A}_{4} \mathrm{e}^{-\alpha_{4} t}\right)$. Cumulative fecal radioactivity (fraction of dose) $=\lambda_{f} \int\left(\mathrm{A}_{1} \mathrm{e}^{-\alpha_{1} \mathrm{t}}+\mathrm{A}_{2} \mathrm{e}^{-\alpha_{2} \mathrm{t}}\right.$ $+\mathrm{A}_{3} \mathrm{e}^{-a_{3} t}+\mathrm{A}_{4} \mathrm{e}^{-a_{4} t}$ ). Ankle radioactivity (counts per minute) $=\mathrm{B}_{1} \mathrm{e}^{-\alpha_{1} \mathrm{t}}+\mathrm{B}_{2} \mathrm{e}^{-\alpha_{2} t}+\mathrm{B}_{3} \mathrm{e}^{-\alpha_{3} t}+\mathrm{B}_{4} \mathrm{e}^{-\alpha_{4} t}+\mathrm{B}_{5}$. Thigh radioactivity (counts per minute) $=\mathrm{C}_{1} \mathrm{e}^{-\alpha_{1} t}$ $+\mathrm{C}_{2} \mathrm{e}^{-\alpha_{2} \mathrm{t}}+\mathrm{C}_{3} \mathrm{e}^{-\alpha_{3} \mathrm{t}}+\mathrm{C}_{4} \mathrm{e}^{-\alpha_{4} t}+\mathrm{C}_{5}$.

For the first three types of data, experiments on ten normal individuals were available. For the last two types of data, experiments on five normal individuals were available. After the data fitting was accomplished, the parameters obtained were averaged, as described in Computational procedures, to obtain the following weighted mean values ( \pm standard deviation).

$$
\begin{array}{llll}
\mathrm{A}_{1}=0.486 \pm 0.096 & \alpha_{1}=58 . & \pm 6 . & \mathrm{K}_{1}=0.79 \pm 0.10 \\
\mathrm{~A}_{2}=0.316 \pm 0.061 & \alpha_{2}=3.8 \quad \pm 0.9 & \alpha_{\mathrm{n}}=0.21 \pm 0.09 \\
\mathrm{~A}_{3}=0.141 \pm 0.047 & \alpha_{3}=0.35 \pm 0.10 & \alpha_{\mathrm{f}}=0.13 \pm 0.03 \\
\mathrm{~A}_{4}=0.057 \pm 0.034 & \alpha_{4}=0.068 \pm 0.034 &
\end{array}
$$

To obtain standard errors of the means, divide the standard deviations above by $\sqrt{10}$ and the standard deviations below by $\sqrt{5}$.

$$
\begin{array}{ll}
\mathrm{B}_{1}=-14 \pm 37 & \mathrm{C}_{1}=7 \pm 32 \\
\mathrm{~B}_{2}=-114 \pm 53 & \mathrm{C}_{2}=27 \pm 10 \\
\mathrm{~B}_{3}=-88 \pm 96 & \mathrm{C}_{3}=-2 \pm 27 \\
\mathrm{~B}_{4}=201 \pm 101 & \mathrm{C}_{4}=72 \pm 55 \\
\mathrm{~B}_{5}=35 \pm 49 & \mathrm{C}_{5}=25 \pm 23
\end{array}
$$

These average parameters for sums of exponentials are equivalent to the average parameters for the compartmental models given in Figure 7 and Tables II and III.

Part 2. Using the average normal parameter values for the compartmental models, artificial data were generated corresponding to the usual sampling times. This produced a set of average "data" for the use of other investigators who may wish to analyze normal calcium kinetics in different ways. To make these average data more representative of the individual experiments from which they derive, a random scatter of the data was introduced. This scatter amounts to 5 to $10 \%$, which was the average scatter observed in fitting the true data to the compartmental models. The simulated data are tabulated below.

$\begin{array}{lccc}\text { Traction of } & & \text { Blood } \\ \text { Time } & \begin{array}{c}\text { Fraction of } \\ \text { dom Ca }\end{array} & \text { Time } & \text { gram Ca } \\ 0.0007 & 0.777 & 0.084 & 0.326 \\ 0.0014 & 0.739 & 0.126 & 0.315 \\ 0.0021 & 0.741 & 0.189 & 0.282 \\ 0.0028 & 0.742 & 0.252 & 0.254 \\ 0.0035 & 0.675 & 0.336 & 0.209 \\ 0.0042 & 0.759 & 0.420 & 0.182 \\ 0.0056 & 0.665 & 0.504 & 0.176 \\ 0.0077 & 0.639 & 1.0 & 0.122 \\ 0.0105 & 0.541 & 1.5 & 0.110 \\ 0.014 & 0.579 & 2.0 & 0.0989 \\ 0.021 & 0.542 & 3.0 & 0.0804 \\ 0.0315 & 0.439 & 4.0 & 0.0616 \\ 0.042 & 0.398 & 5.0 & 0.0561 \\ 0.056 & 0.340 & 6.0 & 0.0453 \\ 0.070 & 0.339 & 7.0 & 0.0402\end{array}$

Time

3.375

4.375

5.375

6.375

7.375

8.375

9.375

10.375

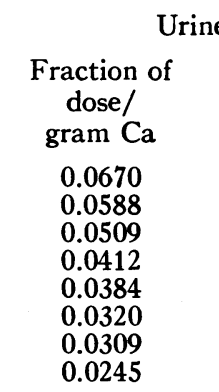

Time

Fraction of dose/ gram $\mathrm{Ca}$

0.0237

0.0201

0.0205

0.0173

0.0165

0.0140

0.0126

0.0115

\begin{tabular}{lccc} 
& \multicolumn{2}{c}{ Urine } & \\
Time & $\begin{array}{c}\text { Cumulative } \\
\text { fraction } \\
\text { of dose }\end{array}$ & Time & $\begin{array}{c}\text { Cumulative } \\
\text { fraction } \\
\text { of dose }\end{array}$ \\
0.125 & 0.0139 & 5.875 & 0.15 \\
0.250 & 0.0230 & 6.875 & 0.159 \\
0.375 & 0.0301 & 7.875 & 0.173 \\
0.500 & 0.0368 & 8.875 & 0.180 \\
0.625 & 0.0398 & 9.875 & 0.186 \\
0.875 & 0.0485 & 10.875 & 0.192 \\
1.0 & 0.0528 & 11.875 & 0.196 \\
1.125 & 0.0644 & 12.875 & 0.206 \\
1.250 & 0.0607 & 13.875 & 0.212 \\
1.375 & 0.0668 & 14.875 & 0.215 \\
1.500 & 0.0664 & 15.875 & 0.222 \\
1.625 & 0.0805 & 16.875 & 0.224 \\
1.875 & 0.0794 & 17.875 & 0.226 \\
2.875 & 0.102 & 18.875 & 0.231 \\
3.875 & 0.126 & 19.875 & 0.234 \\
4.875 & 0.138 & &
\end{tabular}




$\begin{array}{cl} & \begin{array}{c}\text { Cumulative } \\ \text { fraction } \\ \text { of dose }\end{array} \\ \text { Time } & 0.149\end{array}$

Surface, net counts per minute

$\begin{array}{ccrrrr}\text { Time } & \text { Ankle } & \text { Thigh } & \text { Time } & \text { Ankle } & \text { Thigh } \\ 0.0014 & 26.8 & 111.0 & 0.189 & 85.6 & 102.0 \\ 0.0028 & 24.9 & 139.0 & 0.252 & 102.0 & 86.5 \\ 0.0042 & 30.9 & 124.0 & 0.336 & 122.0 & 91.3 \\ 0.0056 & 28.9 & 106.0 & 0.420 & 131.0 & 84.4 \\ 0.0070 & 29.3 & 134.0 & 0.504 & 133.0 & 83.9 \\ 0.0084 & 25.5 & 104.0 & 1.000 & 131.0 & 72.8 \\ 0.0105 & 32.8 & 121.0 & 1.2 & 150.0 & 75.4 \\ 0.0126 & 32.3 & 123.0 & 1.4 & 120.0 & 77.9 \\ 0.0147 & 31.2 & 116.0 & 2.0 & 129.0 & 85.0 \\ 0.0175 & 37.2 & 88.8 & 2.5 & 148.0 & 61.4 \\ 0.0210 & 41.4 & 96.2 & 3.0 & 146.0 & 65.1 \\ 0.0245 & 44.1 & 110.0 & 4.0 & 132.0 & 66.1 \\ 0.0280 & 46.9 & 117.0 & 5.0 & 125.0 & 71.9 \\ 0.0315 & 46.6 & 110.0 & 6.0 & 132.0 & 71.1 \\ 0.0350 & 41.0 & 99.4 & 7.0 & 127.0 & 50.6 \\ 0.0385 & 45.1 & 98.0 & 8.0 & 101.0 & 44.4 \\ 0.0420 & 44.6 & 98.7 & 9.0 & 95.1 & 45.3 \\ 0.0490 & 55.0 & 107.0 & 10.0 & 111.0 & \\ 0.0560 & 56.5 & 104.0 & 11.0 & 116.0 & \\ 0.0700 & 60.2 & 93.7 & 12.0 & 105.0 & \\ 0.0840 & 61.9 & 82.8 & 13.0 & 96.4 & \\ 0.126 & 68.8 & 118.0 & 14.0 & 99.6 & \end{array}$

Because of the great expenditure of time and money in studies of this sort, the authors would like to propose a sharing of data among workers in the field. Raw data for these ten normal men can be obtained by writing to Dr. Neer.

\section{Acknowledgments}

The success of these studies is due largely to the enthusiastic efforts of Mrs. Millicent Bean, Miss Elaine Gaddis, Mrs. Alnora Granger, Mrs. Eileen Jones, Mrs. Diane Shuck, Mrs. Ruth Vreeland, Mr. George Washington, and the entire staff of the Metabolism Ward of the National Cancer Institute. To them we wish to express our sincere thanks and appreciation. We would also like to acknowledge the valuable advice of Mrs. Marjory Weiss and the advice and encouragement of Dr. Nathaniel Berlin.

\section{References}

1. Bauer, G. C. H., A. Carlsson, and B. Lindquist. Evaluation of accretion, resorption and exchange reactions in the skeleton. Kungl. Fysiografiska Sallskapets I Lund Forhandlingar 1955, 25, 3.

2. Bauer, G. C. H., A. Carlsson, and B. Lindquist. Bone salt metabolism in humans studied by means of radiocalcium. Acta med. Scand. 1957, 158, 143.

3. Heaney, R. P., G. C. H. Bauer, F. Bronner, J-F. Dymling, F. W. Lafferty, B. E. C. Nordin, and C. Rich. A normal reference standard for radiocalcium turnover and excretion in humans. J. Lab. clin. Med. 1964, 64, 21.

4. Reifenstein, E. C., Jr., F. Albright, and S. L. Wells. The accumulation, interpretation, and presentation of data pertaining to metabolic balances, notably those of calcium, phosphorus, and nitrogen. $\mathrm{J}$. clin. Endocrl. 1945, 5, 367, and erratum 1946, 6, 232.

5. Lazor, M. Z., L. E. Rosenberg, and P. P. Carbone. Studies of calcium metabolism in multiple myeloma with calcium $^{47}$ and metabolic balance techniques. J. clin. Invest. 1963, 42, 1238.

6. Loevinger, R., and M. Berman. Efficiency criteria in radioactivity counting. Nucleonics 1951, 9, 26.

7. Lutwak, L., and B. T. Burton. Fecal dye markers in metabolic balance studies. The use of brilliant blue and methylcellulose for accurate separation of stool periods. Amer. J. clin. Nutr. 1964, 14, 109.

8. Kochakian, C. D., and R. P. Fox. Microdetermination of calcium by titration of oxalate with ammonium hexanitratocerate. Indus. engin. Chem. (analyst. Ed.) 1944, 16, 762.

9. Aubert, J. F., and G. Milhaud. Méthode de mesure des principales voies du métabolisme calcique chez l'homme. Biochim biophys. Acta (Amst.) 1960, 39, 122.

10. Aubert, J. P., F. Bronner, and L. J. Richelle. Quantitation of calcium metabolism. Theory. J. clin. Invest. 1963, 42, 885.

11. Hearon, J. Z. Theorems on linear systems. Ann. N. Y. Acad. Sci. 1963, 108, 36.

12. Berman, M., and R. Schoenfeld. Invariants in experimental data on linear kinetics and the formulation of models. J. appl. Physics 1956, 27, 1361.

13. Berman, M., E. Shahn, and M. F. Weiss. The routine fitting of kinetic data to models: a mathematical formalism for digital computers. Biophys. J. 1962, 2, 275.

14. Berman, M., M. F. Weiss, and E. Shahn. Some formal approaches to the analysis of kinetic data in terms of linear compartmental systems. Biophys. J. 1962, 2, 289.

15. Berman, M. Compartmental analysis in kinetics in Computers in Biomedical Research, R. Stacey and B. Waxman, eds. New York, Academic Press, 1965, vol. 2, chap. 7.

16. Bronner, F., R. S. Harris, C. J. Maletskos, and C. E. Benda. Studies in calcium metabolism. The fate of intravenously injected radiocalcium in human beings. J. clin. Invest. 1956, 35, 78.

17. Marshall, J. H. Theory of alkaline earth metabolism. Argonne National Laboratories 6646, February 1966, p. 5.

18. Maletskos, C. J. A study of the dynamics of calcium metabolism in dogs. Thesis, Massachusetts Institute of Technology, 1954.

19. Cohn, S. H., S. W. Lippencott, E. A. Gusmano, and J. S. Robertson. Comparative kinetics in $\mathrm{Ca}^{47}$ and $\mathrm{Sr}^{85}$ in man. Radiat. Res. 1963, 19, 104.

20. Cohn, S. W., S. Bozzo, N. Glatstein, C. Constantinides, J. Litvak, and E. A. Gusmano. Formulation of a compartmental model in a study of partial parathyroid deficiency. Metabolism 1964, 13, 1356. 
21. Cohn, S. H., S. Bozzo, J. E. Jesseph, C. Constantinides, D. R. Huene, and E. A. Gusmano. Formulation and testing of a compartmental model for calcium metabolism in man. Radiat. Res. 1965, 26, 319.

22. Bauer, G. C. H., and R. D. Ray. Kinetics of strontium metabolism in man. J. Bone Jt. Surg. 1958, 40A, 171.

23. Krane, S. M., G. L. Brownell, J. B. Stanbury, and H. Corrigan. The effect of thyroid disease on calcium metabolism in man. J. clin. Invest. 1956, 35, 874.

24. Dow, E. C., and J. B. Stanbury. Strontium and calcium metabolism in metabolic bone diseases. $\mathrm{J}$. clin. Invest. 1960, 39, 885.

25. Jasinski, W. K., J. Tolwinski, J. Szymendera, J. Melinowski, J. Nowosielski, J. Makolska, and B. Gwiazdowska. Calcium kinetics in patients with bone tumours in Medical Uses of ${ }^{17} \mathrm{Ca}$. International Atomic Energy Agency Technical Reports Series no. 10, Vienna, 1962 , pp. 68-69.

26. Glass, H. I., and B. E. C. Nordin. The analysis of radio-isotope clearance data obtained using bone seeking isotopes. Phys. in Med. Biol. 1963, 8, 387.

27. Berman, $M$. The formulation and testing of models. Ann. N. Y. Acad. Sci. 1963, 108, 182.

28. Cohn, S. H. Personal communication.

29. Heaney, R. P. Evaluation and interpretation of calcium-kinetic data in man. Clin. Orthop. 1963, 31, 153.

30. Pettigrew, K. D. Estimation of a parameter from observations with unequal precisions in the presence of nuisance parameters. Thesis, George Washington University, 1964.

31. Raiffa, H., and R. Schlaifer. Applied Statistical Decision Theory. Proc. Harvard University Press, Boston, 1961.

32. Symposium on Human Calcium Requirements. AMA Council on Foods and Nutrition. J. Amer. Med. Ass. 1963, 185, 588.

33. Briscoe, A. M., and C. Ragan. Dissimilar distribution of calcium isotopes in blood serum and urine. J. appl. Physiol. 1965, 20, 453.

34. Heaney, R. P., and G. D. Whedon. Radiocalcium studies on bone formation rate in human metabolic bone disease. J. clin. Endocr. 1958, 18, 1246.

35. Forbes, R. M., H. H. Mitchell, and A. R. Cooper. Further studies on the gross composition and mineral elements of the adult human body. J. biol. Chem. 1956, 223, 969.

36. Heaney, R. P. Rate of calcium equilibrium in human tissues (abstract). J. Lab. clin. Med. 1962, 60, 882.

37. Berman, M. Incomplete Data and Models. Proc. 6th IBM Medical Symposium, Brookhaven, N. Y., October 5-8, 1964. 